\title{
Altered NEP2 Expression and Activity in Mild Cognitive Impairment and Alzheimer's Disease
}

\author{
Jeffrey Y. Huang ${ }^{\mathrm{a}}$, Daniel M. Hafez ${ }^{\mathrm{a}}$, Bryan D. James ${ }^{\mathrm{b}}$, David A. Bennett ${ }^{\mathrm{b}}$, and Robert A. \\ Marr $^{\mathrm{a}}$

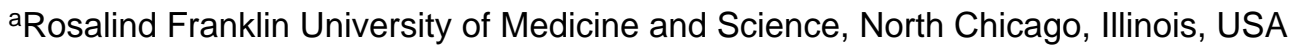 \\ ${ }^{b}$ Rush Alzheimer's Disease Center, Rush University Medical Center, Chicago, Illinois, USA
}

\section{Abstract}

Neprilysin-2 (NEP2), a close homolog of neprilysin (NEP), degrades amyloid- $\beta$ (A $\beta$ ) and serves an important role in clearing $A \beta$ in vivo. We measured NEP2 and NEP mRNA levels from nonimpaired (NI), mild cognitive impaired (MCI), and clinical Alzheimer's disease (AD) subjects in the mid-temporal gyrus, mid-frontal gyrus, caudate, and cerebellum. NEP2 activity levels were also determined. Our results indicate that NEP2 and NEP mRNA expression is altered in MCI subjects relative to NI subjects in AD-susceptible regions. NEP2 enzymatic activity was lowered in association with MCI and $\mathrm{AD}$ and was positively associated with level of cognitive function, independent of diagnostic category. Our finding that NEP2 expression and activity are altered in $\mathrm{MCI}$ is significant as these changes may potentially serve as preclinical markers for $\mathrm{AD}$ and reduced NEP2 activity may be associated with the development of AD.

\section{Keywords}

Alzheimer's disease; amyloid- $\beta$ peptide; biomarker; human brain; neprilysin; neprilysin- 2

\section{Introduction}

\begin{abstract}
Alzheimer's disease (AD) is a progressive neurodegenerative disorder linked to accumulation of amyloid- $\beta$ peptide $(A \beta)$. The inability to effectively clear cerebral $A \beta$ is believed to contribute to AD pathology [1,2]. Previous studies have characterized multiple A $\beta$-degrading enzymes [3]. However, only chemical inhibition of the neprilysin (NEP)-like class of enzymes led to dramatic elevations of $A \beta$ levels in rodents. To verify the importance of the NEP-like protease termed neprilysin-2 (NEP2) in A $\beta$ clearance, we previously demonstrated that NEP2 was able to degrade both $A \beta_{42}$ and $A \beta_{40}$ in vitro [4] and that NEP2 knockout mice exhibited increased A $\beta$ load [5]. Previous studies have measured NEP levels in human brain tissue in relation to AD and aging [3]. However, NEP2 levels (mRNA and activity) have not been examined in this way. Thus, we measured NEP2 in non-impaired (NI), mild cognitive impaired (MCI), and clinical AD human brain tissue from two ADsusceptible (mid-temporal gyrus (MTG) and mid-frontal gyrus (MFG)) and two ADresistant regions (caudate and cerebellum).
\end{abstract}

Correspondence to: Robert A. Marr, Rosalind Franklin University of Medicine and Science, 3333 Green Bay Road, North Chicago, IL 60064, USA; Tel: 847-578-8541, Fax: 847-578-8515, Robert.Marr@ rosalindfranklin.edu.

Authors' disclosures available online (http://www.j-alz.com/disclosures/view.php?id=1005). 


\section{Methods}

\section{Brain tissue and clinical case information}

Frozen postmortem brain tissue from the MTG, MFG, caudate, and cerebellum was acquired from participants of Rush Alzheimer Disease Center's Religious Orders study who underwent annual clinical evaluations [6]. Scores on a battery of 19 neuropsychological tests were used to create summary indices of global cognition as well as 5 specific cognitive domains (episodic memory, working memory, semantic memory, perceptual speed, visuospatial ability) [6]. Diagnostic classification followed a multistep procedure as previously described [7]. Following death, all available clinical data were reviewed by an expert neurologist blinded to neuropathology and a clinical diagnosis was rendered. MTG and MFG samples were examined from $29 \mathrm{NI}, 28 \mathrm{MCI}$, and 23 AD cases as previously diagnosed [8]. Caudate and cerebellar samples were examined from $12 \mathrm{NI}, 10 \mathrm{MCI}$, and 11 AD cases. Specimen data included age (NI: $83.3 \pm 5.7$, MCI: $87.9 \pm 6.3$, AD: $88.9 \pm 6.5$ [y, mean $\pm \mathrm{SD}]$ ) and postmortem interval (NI: 5:18 \pm 0:45, MCI: 6:57 \pm 0:55, AD: 7:25 $\pm 1: 23$ [h:min, mean $\pm \mathrm{SD}]$ ).

\section{PCR Analyses}

For quantitative real time PCR analysis, RNA was isolated from dissected frozen tissue according to the TRIzol ${ }^{\circledR}$ reagent (Invitrogen) protocol. $4 \mu \mathrm{g}$ of DNase-I (DNA-free kit ${ }^{\mathrm{TM}}$, Ambion) treated RNA was reverse transcribed with MultiScribe ${ }^{\mathrm{TM}}$ Reverse Transcriptase (High Capacity cDNA Reverse Transcription Kit, Applied Biosystems) to produce cDNA. Brain tissue cDNA was amplified in triplicate by quantitative real-time PCR (qRT-PCR) using a SYBR Green detection reagent (Power SYBR Green, Applied Biosystems) and human NEP2 (5'-GGAGGCATTGGGATGGTG-3' (bp 2027-2044), 5'CCGGCCATTGTCGTCAA-3' (bp 2070-2086)) (5 uM each primer), NEP (5'CCTGGAGATTCATAATGGATCTTGT-3' (bp 1302-1326), 5'TTGCGGAAAGCATTTCTGG-3' (bp 1356-1374)) (5 uM each primer)), and HPRT (5'GGACAGGACTGAACGTCTTGC-3' (bp 296-316), 5'CTTGAGCACACAGAGGGCTACA-3' (bp 353-374)) (5 uM each primer) specific primers according to the following PCR program: $50^{\circ} \mathrm{C}-2 \mathrm{~min}, 95^{\circ} \mathrm{C}-10 \mathrm{~min}, 40$ cycles of $95^{\circ} \mathrm{C}$ $-15 \mathrm{sec}$ then $60^{\circ} \mathrm{C}-1 \mathrm{~min}$. Hypoxanthine-guanine phosphoribosyltransferase (HPRT) has been shown to serve as an excellent internal reference gene in the brain $[9,10]$. HPRT is a transferase that catalyzes conversion of hypoxanthine to inosine monophosphate and guanine to guanosine monophosphate in the generation of purine nucleotides through the purine salvage pathway [11]. Relative quantification of NEP2 and NEP gene expression was measured by the comparative $\Delta \mathrm{C}_{\mathrm{t}}$ method. qRT-PCR was performed at the Real-Time Quantitative PCR Support Facility at Rosalind Franklin University of Medicine and Science. For endpoint PCR analysis of peripheral blood mononuclear cells (PBMC), cDNA samples were amplified using Taq polymerase (GoTaq ${ }^{\circledR}$ Green Master Mix, Promega) and human NEP2-specific primers and visualized with UV after electrophoresis in ethidium bromide agarose gels.

\section{Enzymatic activity assay}

Total protein was isolated from $\sim 150 \mathrm{mg}$ of tissue according to the T-PER lysis buffer (Pierce) protocol. Protein concentration was measured by BCA protein assay (Pierce). Protein lysates were precleared with protein-G sepharose beads (Protein-G Sepharose 4 Fast Flow, GE Healthcare) prior to immunoprecipitation (IP). Precleared protein lysates were then subjected to IP with protein-G sepharose beads and either goat polyclonal anti-NEP2 (AF2340, R\&D Systems) or goat polyclonal anti-GFP (sc-5385, Santa Cruz Biotechnology) antibody. Fluorogenic peptide substrate (MCA-RPPGFSAFK-[Dnp]-OH, R\&D Systems) was added to IP protein lysates to determine overall enzymatic activity. Fluorescent activity 
was measured using $320 \mathrm{~nm}$ excitation and $405 \mathrm{~nm}$ emission wavelengths over a $5 \mathrm{~min}$ timeframe of 10 kinetic cycles on a microplate reader. According to the fluorogenic peptide substrate protocol (R\&D Systems), overall enzymatic activity was determined by the following equation:

$$
\begin{aligned}
& \text { Specific Activity }(\text { pmoles } / \mathrm{min} / \mu \mathrm{g}) \\
& =\text { Adjusted Vmax }(\mathrm{RFU} \\
& / \max ) \times \text { Conversion Factor }(\text { pmole } \\
& / \mathrm{RFU}) / \text { protein concentraion }(\mu \mathrm{g}) .
\end{aligned}
$$

NEP2 enzymatic activity was then assessed by the difference between the enzymatic activity of anti-NEP2 IP samples and that of anti-GFP IP samples.

\section{Statistics}

We applied one-way ANOVA analysis to test for differences across subjects followed by post hoc tests of multiple comparisons when ANOVA analysis differences were significant $(\mathrm{p}<0.05)$. Linear regression models adjusted for age, gender, and education were used to test the association between cognitive function proximal to death and mRNA expression or enzyme activity, independent of diagnostic category. SigmaPlot 12 software (Systat Software) and SAS version 9.2 (SAS Institute Inc., Cary, NC, 2009) were used.

\section{Results \\ NEP2 and NEP mRNA expression is altered in mid-temporal and mid-frontal gyri of $\mathrm{MCl}$ subjects}

NEP2 mRNA expression was significantly elevated in males with MCI, when compared to NI males, in both the MTG and MFG (Fig. 1A). Conversely, NEP2 mRNA expression was lower in MCI females in the MTG when compared to NI females. A clear trend towards lower NEP2 expression was also seen for MCI and AD females in the MFG (Fig. 1A). NEP mRNA expression was also significantly higher in MCI males relative to NI males in the MTG (Fig. 1B). In MCI females, NEP mRNA expression was significantly lower relative to NI females in the MTG (Fig. 1B). Significant differences between NI, MCI, and AD were not found in the caudate and cerebellum likely due to smaller sample sizes (data not shown). When comparing within cognitive groups we found that NI females expressed more NEP2 mRNA compared to males in the MTG, while the contrary was true for MCI (the latter finding was also observed in NEP mRNA levels) (Fig. 1A, B). NEP2 and NEP mRNA levels (independent of diagnostic classification and gender) were compared across all brain regions in order to further understand overall NEP2 and NEP distribution. Both NEP2 and NEP mRNA levels were highest in the caudate. NEP2 mRNA levels were lowest in the cerebellum while NEP mRNA levels were lowest in the MTG (Fig. 1C). For NEP2 mRNA to be investigated as a blood expression marker for $\mathrm{AD}$, it must first be shown that it is expressed at detectable levels in blood. To determine this, human PBMC cDNA samples from three NI subjects were amplified by PCR with the qRT-PCR NEP2 primers. NEP2expressing 293T cells were used as a positive control. Mock reverse-transcription was used as the negative control. Our results indicate that NEP2 expression can be detected in human PBMC cDNA by specific PCR (Fig. 2A).

\section{NEP2 activity is reduced in mid-temporal and mid-frontal gyri of $\mathrm{MCl}$ and $A D$ subjects}

We measured NEP2 enzymatic activity in NI, MCI, and AD tissue homogenates by using an immunoprecipitation/fluorogenic substrate enzymatic activity assay. In the MTG, NEP2 
activity was significantly lower in males with $\mathrm{AD}$ and $\mathrm{MCI}$ relative to NI males. NEP2 activity was also significantly lower in MCI females relative to NI females in the MTG (Fig. $3 \mathrm{~A})$. In the MFG, NEP2 activity showed a decreasing non-significant trend correlated with clinical diagnosis (NI>MCI $>\mathrm{AD}$ ) for both male and female groups (Fig. 3B). Genderindependent comparison of NI, MCI, and AD groups revealed significant decreases in NEP2 activity in the MTG of MCI and AD groups relative to the NI group as well as a significant decrease in NEP2 activity in the MFG of the AD group relative to the NI group (Fig. 3C). Although in vitro overexpressed NEP2 protein could be detected and concentrated by IPWestern blot (Fig. 2B), it should be noted that endogenous NEP2 protein was not directly detectable by IP-Western. This activity assay was shown to be specific for NEP2 and did not cross react with NEP as we were able to remove all detectable recombinant human NEP2 activity by immunodepletion while no recombinant human NEP activity was removed by this process (Fig. 2C, D). Furthermore, activity detected against the fluorogenic peptide is believed to directly correlate with A $\beta$ degrading activity [12-16]. Protein extracts from cells transfected with the inactive $\gamma$-form of human NEP2 showed only background activity while transfected human NEP2- $\beta$ produced $5 \mathrm{pmol} / \mathrm{min} / \mathrm{ug}$ of activity (data not shown).

Linear regression models demonstrated that NEP2 activity in the MFG was positively associated with global cognition (est $=0.48, \mathrm{p}=0.029$ ), as well as episodic memory (est $=0.73$, $\mathrm{p}=0.018$ ), perceptual speed (est $=0.54, \mathrm{p}=0.021$ ), and visuospatial ability (est $=0.64, \mathrm{p}=0.011$ ). $\mathrm{NEP} 2$ activity in the MTG was also associated with episodic memory (est $=0.96, \mathrm{p}=0.006$ ) (tabulated in Fig. 3D, graphs shown in Fig 4).

\section{Discussion}

Our results suggest that MCI subjects may exhibit a sexually dimorphic difference in NEP2 and NEP mRNA expression levels (higher in males, lower in females) relative to their NI counterparts (Fig. 1A, B). The higher levels in MCI males may represent an adaptive response to increased $\mathrm{A} \beta$. Conversely, the lower levels in MCI females may contribute to the development of $\mathrm{AD}$ and increased female susceptibility to AD [17]. NEP expression has been shown to be sex hormone responsive [18-23] and the same may be true of NEP2. However, it is difficult to predict how sex hormones would affect NEP expression in men and women as both androgen and estrogen stimulate NEP expression and because of other potential complications such as hormone replacement therapy. As far as we know, no other study has compared NEP expression between men and women. Furthermore, regulation of NEP2 expression is more difficult to predict as the regulatory elements have yet to be characterized. It is perhaps unlikely that these gender differences can be explained by sex hormones alone as, based on androgen/estrogen levels, lower NEP/NEP2 levels would have been predicted in postmenopausal women. The finding that NEP2 and NEP mRNA expression in AD subjects was similar to that of NI subjects was unexpected. Yet changes in mRNA expression may not necessarily correlate with enzymatic activity due to alternate splicing, translational, and post-translational modifications. Our previous work showed that only one of the three known NEP2 splice forms ( $\beta$ ) degraded A $\beta$ [4] and our qRT-PCR primers detected all isoforms. This makes it difficult to determine from our qRT-PCR analysis alone if these changes in expression are directly involved in $\mathrm{AD}$ pathogenesis. Specific qRT-PCR primers could differentiate between the active NEP2- $\beta$ and inactive NEP2- $\gamma$ forms because of the large missing exon in NEP2 $-\gamma$. However, exclusive qRT-PCR analysis of NEP2- $\beta$ is complicated by the fact it shares all the same sequences with the active-site-lacking NEP2- $\delta$ form (with the exception of a 29 base pair frameshift insertion in NEP2- $\delta$ ), regardless of other potential complications from yet unidentified splice forms [3]. However, since these "global" expression changes occur in MCI, they may be very useful as expression markers predicting risk of $\mathrm{AD}$. In addition to splicing, oxidation can also reduce endopeptidase activity and previous studies have found that NEP and IDE were found in a 
more oxidized and inactive state in AD [24-26]. In support of this, we found that NEP2 enzymatic activity was reduced in association with AD (Fig. 3). Furthermore, analysis independent of diagnostic classification showed that higher NEP2 activity was associated with better cognition. Finally, we cannot rule out that NEP2 expression is altered in general in neurodegenerative diseases as we have not yet included control specimens from other diseases such as Parkinson's disease and frontotemporal dementia.

Our NEP mRNA expression data is at odds with previous studies showing reduced expression in association with $\mathrm{AD}$ and/or aging [3]. One possible explanation for this discrepancy is that these studies used tissues from different sources, species, disease states, and brain regions. In addition, our study used a quantitative real-time PCR approach while most previous studies did not (to date only 6 of approximately 20 NEP expression studies used PCR analysis of cDNA comparing human NI to AD). Most of these previous studies used semiquantitative endpoint PCR [27-31] with the former study supporting our findings [27]. It should also be noted that other studies have also found no change or increased NEP in association with $\mathrm{AD}$ by immunohistochemistry and activity assay [12, 32, 33]; therefore, our finding of unchanged or increased NEP mRNA in AD is not without precedence. As we did not assay NEP activity in this study, we cannot directly compare our findings with NEP activity data from other studies. Since NEP2 activity has not previously been analyzed, we have no precedent for comparison. However, for NEP mRNA expression in the MFG in particular, we expected reduced NEP expression in $\mathrm{AD}$ as previous research using specimens from the same study had demonstrated [16]. Yet our research shows NEP expression in the MFG is not significantly changed in MCI and AD (Fig. 1B), suggesting more work must be done for clarification. Regional expression comparisons (Fig. 1C) showed the highest NEP2 and NEP mRNA levels in the caudate, with NEP mRNA also high the cerebellum, correlating with relative resistance to $A \beta$ pathology. This is contrary to NEP2 expression observed in rats as little to no NEP2 was found in the caudate by in-situ hybridization [34]. However, significant (but relatively lower) levels of NEP2 were found by reverse-transcription-PCR in the rat caudate [35].

In summary, this work is significant because we are the first to measure NEP2 expression and activity in relation to MCI and $\mathrm{AD}$. We found that NEP2 expression and activity was altered in association with MCI. Furthermore, if these changes can also be detected in easily accessible fluids (i.e., blood or cerebrospinal fluid) NEP2 could be used as a preclinical marker for AD. Finally, our analysis of NEP2 activity is functionally relevant to the etiology of $\mathrm{AD}$.

\section{Acknowledgments}

This study was supported by the Alzheimer's Association (NIRG-08-89784) (RAM) and grants P30AG10161 and R01AG15819 from the National Institute on Aging (DAB).

\section{References}

1. Glabe C. Does Alzheimer disease tilt the scales of amyloid degradation versus accumulation? Nat Med. 2000; 6:133-134. [PubMed: 10655093]

2. Mawuenyega KG, Sigurdson W, Ovod V, Munsell L, Kasten T, Morris JC, Yarasheski KE, Bateman RJ. Decreased clearance of CNS $\beta$-amyloid in Alzheimer's disease. Science. 2011; 330:1774. [PubMed: 21148344]

3. Marr RA, Spencer BJ. NEP-like Endopeptidases and Alzheimer's Disease. Curr Alzheimer Res. 2010; 7:223-229. [PubMed: 20088804]

4. Huang JY, Bruno AM, Patel CA, Huynh AM, Philibert KD, Glucksman MJ, Marr RA. Human membrane metallo-endopeptidase-like protein degrades both beta-amyloid 42 and beta-amyloid 40 . Neuroscience. 2008; 155:258-262. [PubMed: 18571334] 
5. Hafez D, Huang JY, Huynh AM, Valtierra S, Rockenstein E, Bruno AM, Lu B, DesGroseillers L, Masliah E, Marr RA. Neprilysin-2 is an important beta-amyloid degrading enzyme. Am J Pathol. 2011; 178:306-312. [PubMed: 21224067]

6. Wilson RS, Beckett LA, Barnes LL, Schneider JA, Bach J, Evans DA, Bennett DA. Individual differences in rates of change in cognitive abilities of older persons. Psychol Aging. 2002; 17:179193. [PubMed: 12061405]

7. Bennett DA, Wilson RS, Schneider JA, Evans DA, Beckett LA, Aggarwal NT, Barnes LL, Fox JH, Bach J. Natural history of mild cognitive impairment in older persons. Neurology. 2002; 59:198205. [PubMed: 12136057]

8. Wang S, Simon BP, Bennett DA, Schneider JA, Malter JS, Wang DS. The significance of Pin1 in the development of Alzheimer's disease. J Alzheimers Dis. 2007; 11:13-23. [PubMed: 17361031]

9. Gubern C, Hurtado O, Rodriguez R, Morales JR, Romera VG, Moro MA, Lizasoain I, Serena J, Mallolas J. Validation of housekeeping genes for quantitative real-time PCR in in-vivo and in-vitro models of cerebral ischaemia. BMC Mol Biol. 2009; 10:57. [PubMed: 19531214]

10. Lee KS, Alvarenga TA, Guindalini C, Andersen ML, Castro RM, Tufik S. Validation of commonly used reference genes for sleep-related gene expression studies. BMC Mol Biol. 2009; 10:45. [PubMed: 19445681]

11. Seegmiller JE, Rosenbloom FM, Kelley WN. Enzyme defect associated with a sex-linked human neurological disorder and excessive purine synthesis. Science. 1967; 155:1682-1684. [PubMed: 6020292]

12. Miners JS, Baig S, Tayler H, Kehoe PG, Love S. Neprilysin and insulin-degrading enzyme levels are increased in Alzheimer disease in relation to disease severity. J Neuropathol Exp Neurol. 2009; 68:902-914. [PubMed: 19606063]

13. Miners JS, Kehoe P, Love S. Neprilysin protects against cerebral amyloid angiopathy and A $\beta$ induced degeneration of cerebrovascular smooth muscle cells. Brain Pathol. 2011; 21:594-605. [PubMed: 21382117]

14. Miners JS, Kehoe PG, Love S. Immunocapture-based fluorometric assay for the measurement of insulin-degrading enzyme activity in brain tissue homogenates. J Neurosci Methods. 2008; 169:177-181. [PubMed: 18221786]

15. Miners JS, van Helmond Z, Kehoe PG, Love S. Changes with age in the activities of beta-secretase and the Abeta-degrading enzymes neprilysin, insulin-degrading enzyme and angiotensinconverting enzyme. Brain Pathol. 2010; 20:794-802. [PubMed: 20175776]

16. Wang S, Wang R, Chen L, Bennett DA, Dickson DW, Wang DS. Expression and functional profiling of neprilysin, insulin-degrading enzyme, and endothelin-converting enzyme in prospectively studied elderly and Alzheimer's brain. J Neurochem. 2010; 115:47-57. [PubMed: 20663017]

17. Barnes LL, Wilson RS, Bienias JL, Schneider JA, Evans DA, Bennett DA. Sex differences in the clinical manifestations of Alzheimer disease pathology. Arch Gen Psychiatry. 2005; 62:685-691. [PubMed: 15939846]

18. Huang J, Guan H, Booze RM, Eckman CB, Hersh LB. Estrogen regulates neprilysin activity in rat brain. Neurosci Lett. 2004; 367:85-87. [PubMed: 15308303]

19. Liang K, Yang L, Yin C, Xiao Z, Zhang J, Liu Y, Huang J. Estrogen stimulates degradation of beta-amyloid peptide by up-regulating neprilysin. J Biol Chem. 2010; 285:935-942. [PubMed: 19897485]

20. Yao M, Nguyen TV, Rosario ER, Ramsden M, Pike CJ. Androgens regulate neprilysin expression: role in reducing beta-amyloid levels. J Neurochem. 2008; 105:2477-2488. [PubMed: 18346198]

21. Shen R, Sumitomo M, Dai J, Hardy DO, Navarro D, Usmani B, Papandreou CN, Hersh LB, Shipp MA, Freedman LP, Nanus DM. Identification and characterization of two androgen response regions in the human neutral endopeptidase gene. Mol Cell Endocrinol. 2000; 170:131-142. [PubMed: 11162897]

22. Zheng R, Shen R, Goodman OB Jr, Nanus DM. Multiple androgen response elements cooperate in androgen regulated activity of the type 1 neutral endopeptidase promoter. Mol Cell Endocrinol. 2006; 259:10-21. [PubMed: 16949732] 
23. Xiao ZM, Sun L, Liu YM, Zhang JJ, Huang J. Estrogen regulation of the neprilysin gene through a hormone-responsive element. J Mol Neurosci. 2009; 39:22-26. [PubMed: 19127446]

24. Caccamo A, Oddo S, Sugarman MC, Akbari Y, LaFerla FM. Age- and region-dependent alterations in Abeta-degrading enzymes: implications for Abeta-induced disorders. Neurobiol Aging. 2005; 26:645-654. [PubMed: 15708439]

25. Wang DS, Iwata N, Hama E, Saido TC, Dickson DW. Oxidized neprilysin in aging and Alzheimer's disease brains. Biochem Biophys Res Commun. 2003; 310:236-241. [PubMed: 14511676]

26. Shinall H, Song ES, Hersh LB. Susceptibility of amyloid beta peptide degrading enzymes to oxidative damage: a potential Alzheimer's disease spiral. Biochemistry. 2005; 44:15345-15350. [PubMed: 16285738]

27. Hellstrom-Lindahl E, Ravid R, Nordberg A. Age-dependent decline of neprilysin in Alzheimer's disease and normal brain: inverse correlation with A beta levels. Neurobiol Aging. 2008; 29:210 221. [PubMed: 17098332]

28. Reilly CE. Neprilysin content is reduced in Alzheimer brain areas. J Neurol. 2001; 248:159-160. [PubMed: 11284139]

29. Russo R, Borghi R, Markesbery W, Tabaton M, Piccini A. Neprylisin decreases uniformly in Alzheimer's disease and in normal aging. FEBS Lett. 2005; 579:6027-6030. [PubMed: 16226260]

30. Yasojima K, Akiyama H, McGeer EG, McGeer PL. Reduced neprilysin in high plaque areas of Alzheimer brain: a possible relationship to deficient degradation of beta-amyloid peptide. Neurosci Lett. 2001; 297:97-100. [PubMed: 11121879]

31. Yasojima K, McGeer EG, McGeer PL. Relationship between beta amyloid peptide generating molecules and neprilysin in Alzheimer disease and normal brain. Brain Res. 2001; 919:115-121. [PubMed: 11689168]

32. Miners JS, Morris S, Love S, Kehoe PG. Accumulation of insoluble amyloid-beta in down's syndrome is associated with increased BACE-1 and neprilysin activities. J Alzheimers Dis. 2011; 23:101-108. [PubMed: 20930275]

33. Wang DS, Lipton RB, Katz MJ, Davies P, Buschke H, Kuslansky G, Verghese J, Younkin SG, Eckman C, Dickson DW. Decreased neprilysin immunoreactivity in Alzheimer disease, but not in pathological aging. J Neuropathol Exp Neurol. 2005; 64:378-385. [PubMed: 15892294]

34. Facchinetti P, Rose C, Schwartz JC, Ouimet T. Ontogeny, regional and cellular distribution of the novel metalloprotease neprilysin 2 in the rat: a comparison with neprilysin and endothelinconverting enzyme-1. Neuroscience. 2003; 118:627-639. [PubMed: 12710972]

35. Ouimet T, Facchinetti P, Rose C, Bonhomme MC, Gros C, Schwartz JC. Neprilysin II: A putative novel metalloprotease and its isoforms in CNS and testis. Biochem Biophys Res Commun. 2000; 271:565-570. [PubMed: 10814502] 
a)

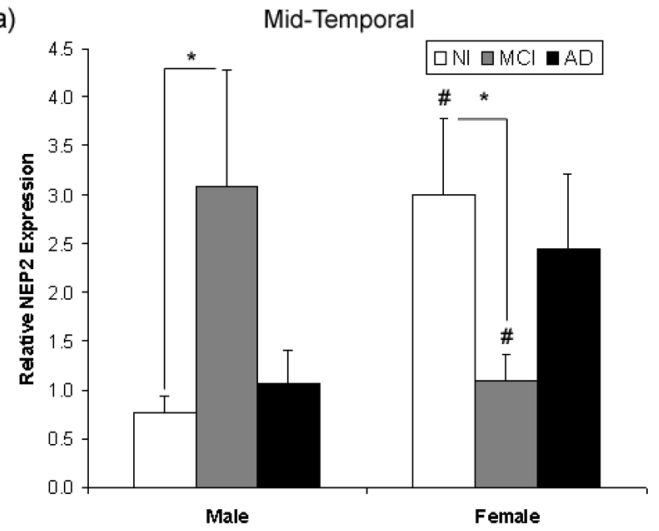

b)
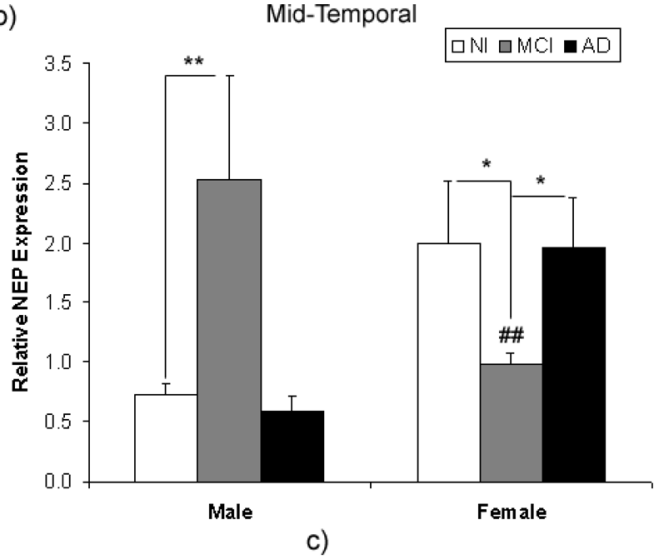

c)

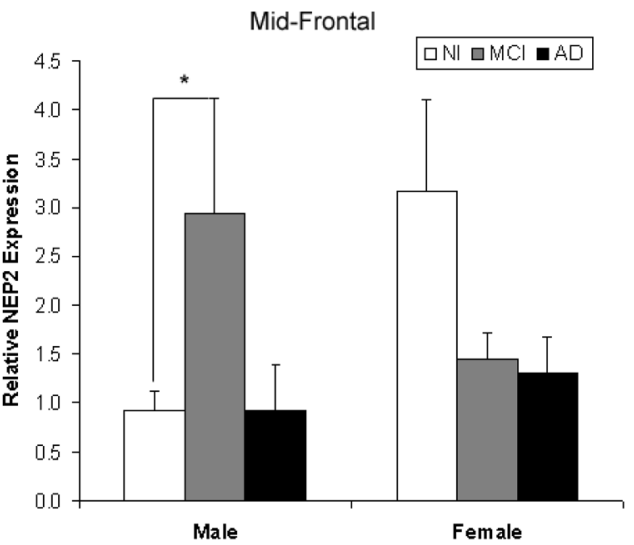

Mid-Frontal

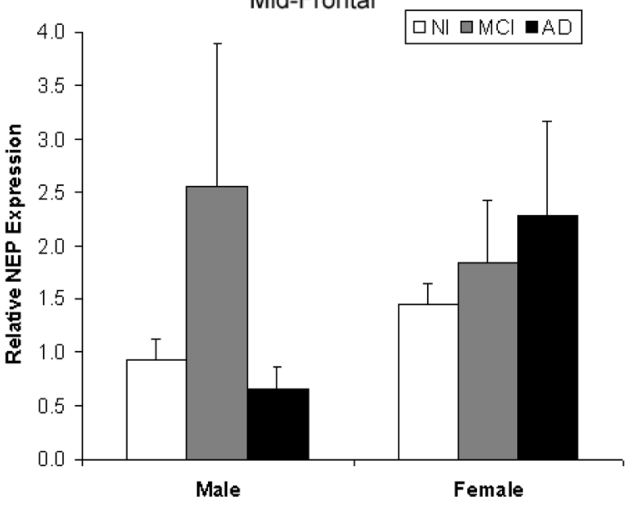

- NEP2 DNEP

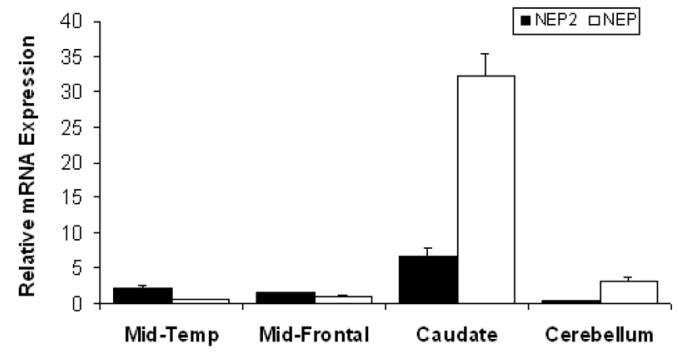

Figure 1. NEP2 and NEP mRNA expression is altered in MCI

(a) NEP2 and (b) NEP mRNA expression in NI, MCI, and AD male and female groups in the MTG and MFG ( $n=12$ for NI males, $n=6$ for MCI males, $n=5$ for AD males, $n=17$ for NI females, $n=22$ for MCI females, $n=18$ for AD females). (c) NEP2 (solid bars) and NEP (open bars) regional mRNA expression levels for the MTG, MFG, caudate, and cerebellum. All NEP2 and NEP regional comparisons were significantly different $(\mathrm{p}<0.05)(\mathrm{n}=80$ for MTG, $n=76$ for MFG, $n=33$ for caudate, $n=33$ for cerebellum). Values are means $\pm S E M$. For cross-diagnostic group comparisons, $* p<0.05$, ** $<<0.01$. For cross-sex classification comparisons within each diagnostic group, \#p<0.05, \#\#p<0.01. 
a)

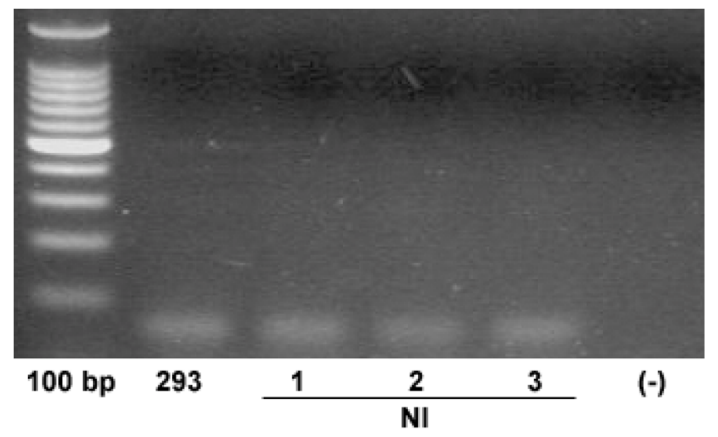

c)

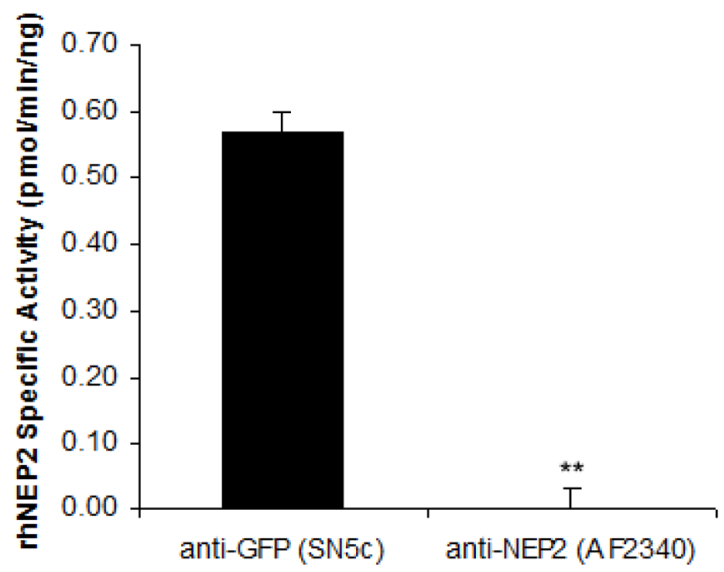

IP Antibody b)

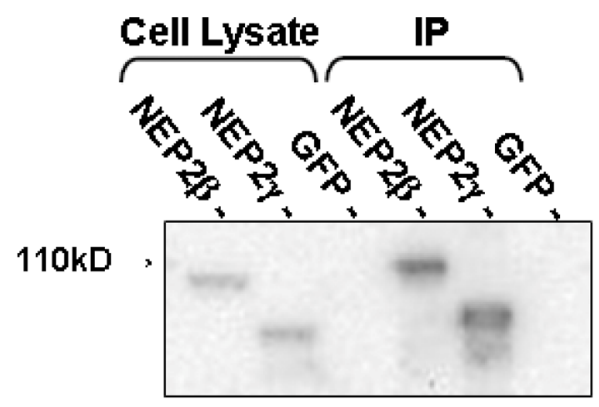

d)

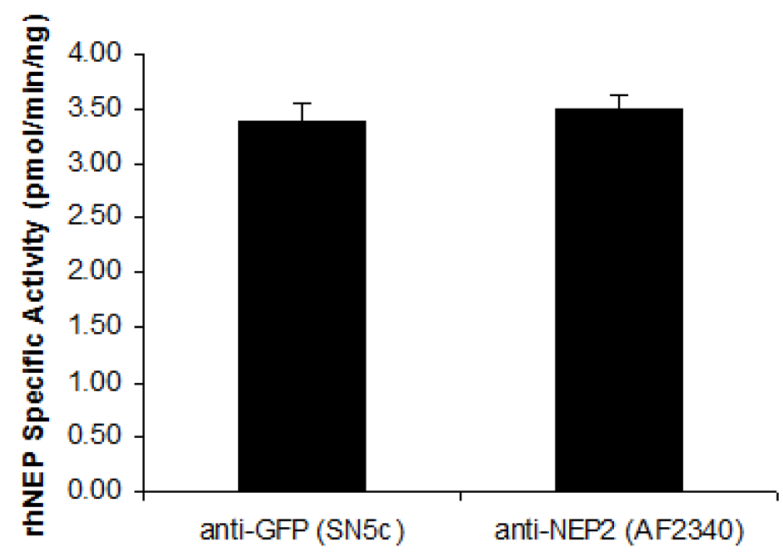

IP Antibody

Figure 2.

a) NEP2 detected in blood cells by endpoint PCR. NEP2 detected in human peripheral blood mononuclear cells (PBMC) of three NI individuals using qRT-PCR NEP2-specific primers. NEP2-expressing 293T (293) cell lysate was used as a positive control and mock reverse transcription (-) was used as a negative control. b) Immunoprecipitation/Western blot hybridization (IP-Western) of NEP2- $\beta$ and NEP2 $-\gamma$. Western blot hybridization of NEP2- $\beta$, NEP2- $\gamma$, and GFP transfected 293T cell lysates (rows $1-3$ ) and NEP2- $\beta$, NEP2- $\gamma$, and GFP transfected 293T cell lysates (rows 4-6) immunoprecipitated with NEP2-specific antibody (AF2340). NEP2- $\beta$ and NEP2- $\gamma$ were both detected in the cell lysate (rows 1-2) and were both present at higher levels following immunoprecipitation (rows 4-5).

c) Recombinant human NEP2 (rhNEP2) immunoprecipitation activity assay. rhNEP2 shows no remaining activity following AF2340 immunoprecipitation validating the specificity of the AF2340 antibody to NEP2. Samples were run in triplicate $(n=3)$. **p<0.01. d) Recombinant human NEP (rhNEP) immunoprecipitation activity assay. rhNEP remains fully active following AF2340 and SN5c immunoprecipitation indicating that there is no cross reactivity of rhNEP to NEP2-specific and GFP-specific antibodies. Samples were run in triplicate $(n=3)$. 
a) b) Mid-Frontal

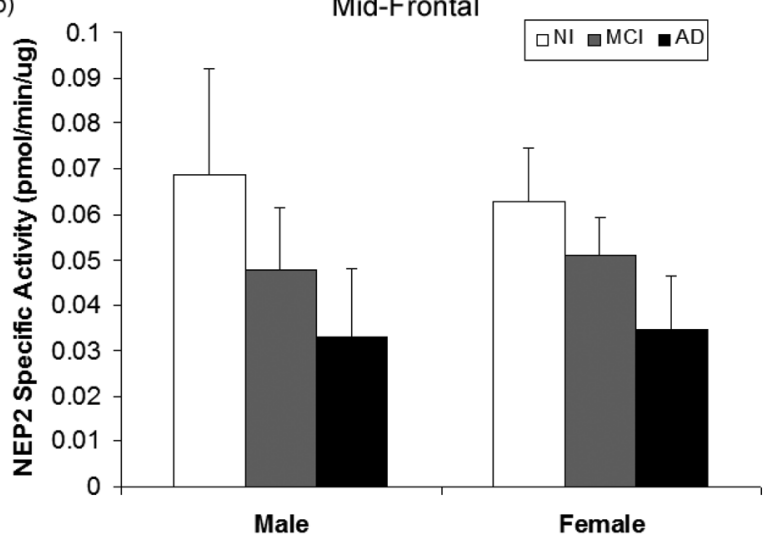

d)

\begin{tabular}{|c|c|c|c|c|c|}
\hline & MFG & & & MTG \\
\hline & $\begin{array}{c}\text { Global } \\
\text { Cognition }\end{array}$ & $\begin{array}{c}\text { Episodic } \\
\text { Memory }\end{array}$ & $\begin{array}{c}\text { Perceptual } \\
\text { Speed }\end{array}$ & $\begin{array}{c}\text { Visuospatial } \\
\text { Ability }\end{array}$ & $\begin{array}{c}\text { Episodic } \\
\text { Memory }\end{array}$ \\
\hline EST & 0.48 & 0.73 & 0.54 & 0.64 & 0.96 \\
\hline$p$ & 0.029 & 0.018 & 0.021 & 0.011 & 0.006 \\
\hline
\end{tabular}

c)

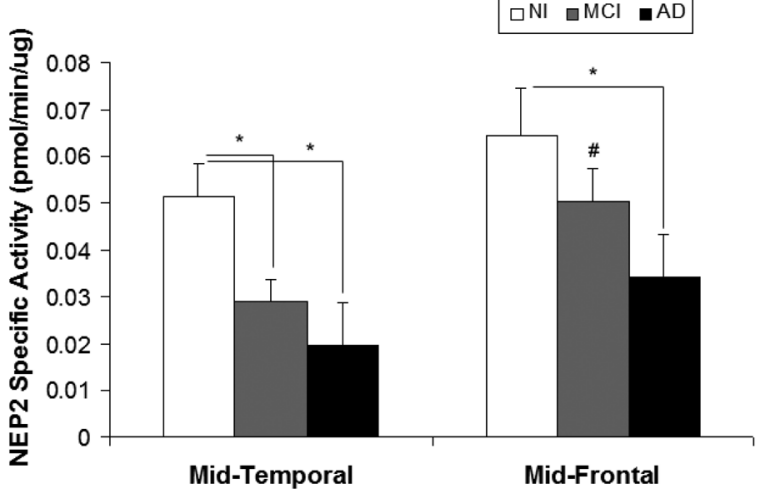

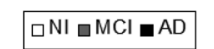

Female

Mid-Frontal

Figure 3. NEP2 activity is reduced in MCI and AD patients

NEP2 activity in the MTG (a) or MFG (b) of NI, MCI, and AD male and female groups as measured by immunoprecipitation/fluorogenic substrate enzymatic activity assay $(\mathrm{n}=4$ for NI males, $n=3$ for MCI males, $n=4$ for AD males, $n=11$ for NI females, $n=15$ for MCI females, $\mathrm{n}=10$ for AD females). (c) Sex-independent comparisons of NEP2 activity in the MTG and MFG of NI, MCI, and AD groups ( $n=15$ for NI, $n=18$ for MCI, $n=14$ for AD). Values are means \pm SEM. For cross-diagnostic group comparisons, ${ }^{*} p<0.05, * * p<0.01$. For cross-sex classification comparisons within each diagnostic group, $\# \mathrm{p}<0.05$, \#\#p<0.01. (d) Linear regression model analysis correlating NEP2 activity in the MFG and MTG with cognitive function domains (EST = estimated slope). 

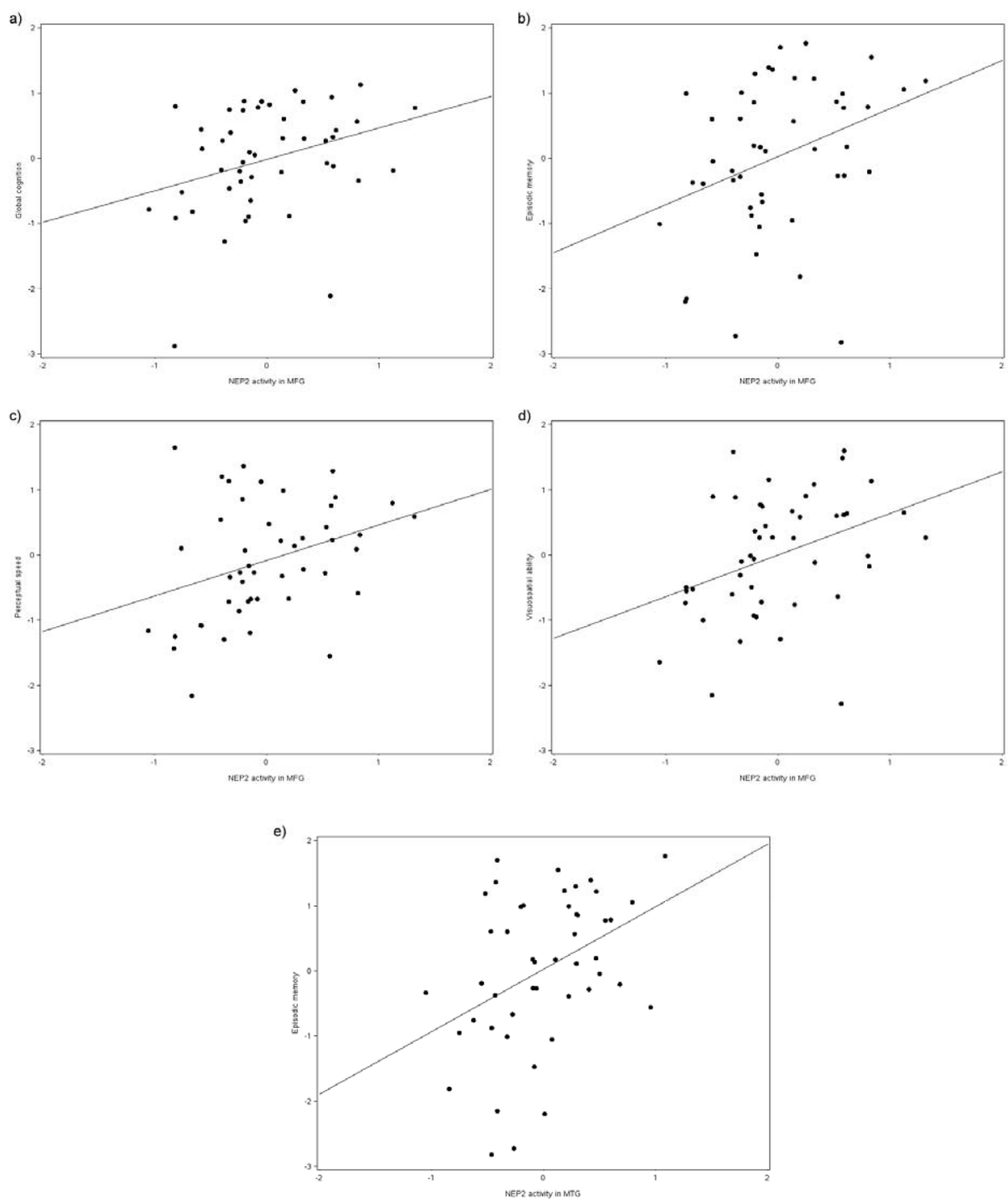

Figure 4.

Linear regression model graphs correlating NEP2 activity with cognitive function domains. NEP2 activity in the MFG shows a positive correlation with global cognition ( $p=0.029)$ (a), episodic memory $(\mathrm{p}=0.018)(\mathrm{b})$, perceptual speed $(\mathrm{p}=0.021)(\mathrm{c})$, and visuospatial ability $(\mathrm{p}=0.011)(\mathrm{d})$. NEP2 activity in the MTG shows a positive correlation with episodic memory $(\mathrm{p}=0.006)(\mathrm{e})$. 